\title{
Dopaminergic Modulation of Visual Attention and Working Memory in the Rodent Prefrontal Cortex
}

\author{
Yogita Chudasama*,' and Trevor W Robbins' \\ 'Department of Experimental Psychology, University of Cambridge, Cambridge, UK
}

\begin{abstract}
Converging evidence suggests that dopaminergic projections to the prefrontal cortex (PFC) modulate both attention and working memory processes that may be related to either insufficient or excessive dopamine activity specific to a $D_{1}$ receptor mechanism. We examined the effects of bilateral intraprefrontal cortical infusions of the $D_{1}$ agonist (SKF 81297) on a novel task specifically designed to assess the animals' ability to attend to a visual target ( 0.7 or $0.5 \mathrm{~s}$ ) and then remember the location of that target over a variable delay ( 0 $16 \mathrm{~s})$ within the same test session. Bilateral prefrontal infusions of the low dose of SKF $81297(0.01 \mu \mathrm{g})$ had no effect on visual attention or memory throughout the entire testing schedule. The medium $(0.06 \mu \mathrm{g})$ dose preferentially increased attention to the stimulus target but only improved memory for that stimulus at a duration of $0.7 \mathrm{~s}$, although in a delay-independent manner. The high dose $(0.3 \mu \mathrm{g})$ of the $D_{1}$ agonist also increased attentional accuracy. However, it was only under the more attention challenging condition $(0.5 \mathrm{~s})$ that this high dose also produced a baseline delay-dependent modulation of memory for the stimulus target. Specifically, good memory at the short delay was impaired and poor memory at the long delay was improved. These data provide the first demonstration that dopamine $D_{\text {, }}$ receptor stimulation sufficient to improve attentional accuracy, can also disrupt, and facilitate short-term working memory performance in a delay-dependent manner.

Neuropsychopharmacology (2004) 29, 1628-1636, advance online publication, 12 May 2004; doi: I 0. I038/sj.npp. I 300490
\end{abstract}

Keywords: rat; attention; working memory; dopamine; modulation; SKF 8I297

\section{INTRODUCTION}

Intact dopaminergic mechanisms in the prefrontal cortex (PFC) modulate many aspects of cognitive performance (Arnsten, 1997, 1998; Robbins, 2000). Mesocortical dopamine (DA) depletion impairs working memory performance in monkeys (Brozoski et al, 1979) and rats (Simon, 1981) implicating an important role for DA in learning and memory processes. The demonstration that intra-PFC infusions of $\mathrm{DA} \mathrm{D}_{1}$, but not $\mathrm{D}_{2}$ receptor antagonists, produce delay-dependent impairments in spatial working memory tasks (Sawaguchi and Goldman-Rakic, 1991; Seamans et al, 1998) identifies a selective $\mathrm{D}_{1}$ receptor mechanism in this behavior.

The inverted ' $U$ '-shaped hypothesis of DA function (Robbins, 1985; Arnsten and Goldman-Rakic, 1990; Arnsten et al, 1994) maintains that mnemonic performance relies on an optimal level of mesocortical DA function (Williams and Goldman-Rakic, 1995; Arnsten, 1997; Zahrt et al, 1997), such

*Correspondence: Dr Y Chudasama, Laboratory of Neuropsychology, National Institute of Mental Health, 49 Convent Drive, Building 49, Room IB80, Bethesda, MD 20892-44I5, USA, Tel: + I 30I 4965625 , Fax: + I 301402 0046, E-mail: yogita@In.nimh.nih.gov

Received 4 February 2004; revised 13 April 2004; accepted 14 April 2004

Online publication: 16 April 2004 at http://www.acnp.org/citations/ Npp04 I 6040405 I/default.pdf that excessive or insufficient $\mathrm{D}_{1} \mathrm{DA}$ receptor stimulation in the PFC is associated with impaired working memory performance (Arnsten, 1997; Zahrt et al, 1997). More recently, Floresco and Phillips (2001) showed that activation of $\mathrm{D}_{1}$ receptors in the PFC can exert differential effects (impairments and improvements) depending on the duration of the delay period, on a task that assessed working memory processes in a delayed version of a radial arm maze.

However, accurate performance in working memory tasks, depends on more than just holding information 'on-line.' Thus, as Goldman-Rakic (1987) argued, the delayed response (DR) test measures at least three subprocesses; (a) accessing appropriate information, (b) holding it on-line, and (c) using it to guide behavior. However, although tests of working memory depend on defining delay-dependent deficits, they do not adequately assess the contribution of other component processes such as mechanisms of attention that presumably allow access to selective information which otherwise would make us illequipped to act coherently in the face of simultaneous sources of stimulation (Parasuraman, 2000). In addition, such attentional processes may be recruited to enable the active maintenance of information within a working memory system (Awh and Jonides, 2001). Those overlapping mechanism of attention and working memory may be differentially affected by fluctuations in prefrontal DA (see Granon et al, 2000; Cools et al, 2002). 
It follows, therefore, that different levels of DA activity may be required for different cognitive processes (Roberts et al, 1994; Collins et al, 1998), so that although dopamine receptor stimulation may improve performance in one task, it may impair performance in another task. Furthermore, different levels of DA may be required to perform component cognitive processes engaged within the same task. This suggests that DA has an important neuromodulatory role and may differentially affect cognitive processes such as impairing memory for a stimulus that has already received selective attention.

Accordingly, we extended the five choice serial reaction time task (5CSRTT) to include a discrete memory component, which allowed for the simultaneous assessment of attention to a visual stimulus and memory for that stimulus over a variable delay. Our novel combinedattention memory (CAM) task is similar to classical delayed response tests of working memory because (a) the information to be remembered in each trial is independent from the next, (b) the response is contingent upon the information that was presented at the beginning of the trial which must be discriminated from subsequently presented stimuli, and (c) the memory load can be altered by varying the delay between the sample and choice phase of each trial. In addition, the CAM task capitalizes on a number of procedural parameters such as brief sample exposure thus placing a high attentional premium, visual modality for stimulus salience, and discrete spatial distractors during the choice phase, which has several advantages over other paradigms such as spatial versions in open mazes where it is not so apparent how attentional impairments may influence mnemonic aspects of performance. In addition, the automated nature of the task confers considerable advantages including the on-line collection and analysis of a wide range of performance measures, the provision of consistency and precision in task parameters such as stimulus duration and delays, and is less labor intensive. Using this task, we examined the effects of intra-PFC infusions of the dopamine agonist SKF 81297 on the rats' ability to detect brief visual targets and then to retain their locations over varying delays. Animals successfully attained over $70 \%$ accuracy at $0.7 \mathrm{~s}$ stimulus duration during the attentional phase (chance performance $=20 \%$ ) and a delay-dependent gradient of about $50-70 \%$ correct during the memory phase (chance performance $=50 \%$ ). Following cannulae implantation, animals were infused with either $0.01,0.06$ or $0.3 \mu \mathrm{g}$ dose of SKF 81297 and were tested under two different stimulus durations $(0.7$ and $0.5 \mathrm{~s})$.

\section{MATERIAL AND METHODS}

\section{Subjects}

All subjects were male Lister Hooded rats (Charles River, UK), housed in pairs in a temperature-controlled room $\left(22^{\circ} \mathrm{C}\right)$, under diurnal conditions $(12 \mathrm{~h}$ light $/ 12 \mathrm{~h}$ dark). Rats were food deprived and maintained at $85 \%$ of their freefeeding weight throughout the experiment. All testing occurred at a regular time during the light period and animals were 3 months of age $(230-260 \mathrm{~g})$ at the start of behavioral training. All experimental procedures were subject to UK Home Office approval (Project Licence PPL 80/1324).

\section{Apparatus}

Six nine-hole boxes (Cambridge Cognition, Cambridge, UK) were used for the CAM task. This apparatus has been described previously (see Carli et al, 1983) and is used primarily to assess continuous performance in rats (Muir et al, 1996; Passetti et al, 2002). In brief, each box was a $25 \times 25 \mathrm{~cm}$ aluminum chamber with an arc of contiguous apertures numbered one to nine (each $2.5 \mathrm{~cm}$ square, $4 \mathrm{~cm}$ deep and set $2 \mathrm{~cm}$ above floor level). Illumination of each hole was provided by a standard $3 \mathrm{~W}$ bulb located at the rear of the hole. In addition, located at the entrance of each aperture was an infrared photocell beam monitoring the nose poke response of the rat. Each aperture could be blocked by a metal cover when not required. For the present study, apertures $1,3,5,7$, and 9 were open. Pellets were delivered into a food magazine that was located in the wall opposite to the visual array. The opening of the food magazine was covered by a hinged Perspex panel door and was monitored by a microswitch. The four chambers were individually housed within sound-attenuating cabinets and were ventilated by low-level noise fans, which also served to mask extraneous background noise. The apparatus and on-line data collection was controlled by means of an Acorn computer system with software written by Dr RN Cardinal.

\section{Behavioral Procedure}

A schematic illustration of the events and performance measures during a single trial in the CAM task is provided in Figure 1. Each trial consisted of two phases, the target (attention) phase and the choice (memory) phase. The target phase was similar to the 5CSRTT (Carli et al, 1983) although the final requirement for the target duration was less stringent $(0.7 \mathrm{~s})$. Rats were trained to discriminate a brief visual stimulus that was presented pseudorandomly in one of the five spatial locations. At the beginning of trial, the house light was illuminated and the trial was initiated by the rat making an entry into the food magazine. After a fixed $5 \mathrm{~s}$ interval, the light at the rear of one of the apertures was illuminated for $0.7 \mathrm{~s}$. A nose poke response in the aperture during illumination and for $5 \mathrm{~s}$ afterwards (the limited hold period) was recorded as a correct response. Responses in a nonilluminated hole during the target presentation period (incorrect response) and failures to respond within the limited hold period (omission) terminated the trial. The next trial began following a $10 \mathrm{~s}$ intertrial interval during which all lights were extinguished.

If the rat made a correct target response, a delay interval was initiated which was signified by the illumination of the food magazine. The animal was required to nose poke the food magazine during the delay. The last nose poke after the delay interval resulted in the choice (memory) phase when two lights were presented simultaneously for $3 \mathrm{~s}$. One choice stimulus light was presented in the hole that was identical to the target light during the attention phase of the trial. The second distractor choice stimulus light was in a location randomly selected from one of the remaining four holes. The relative position of the distractor light in the choice 


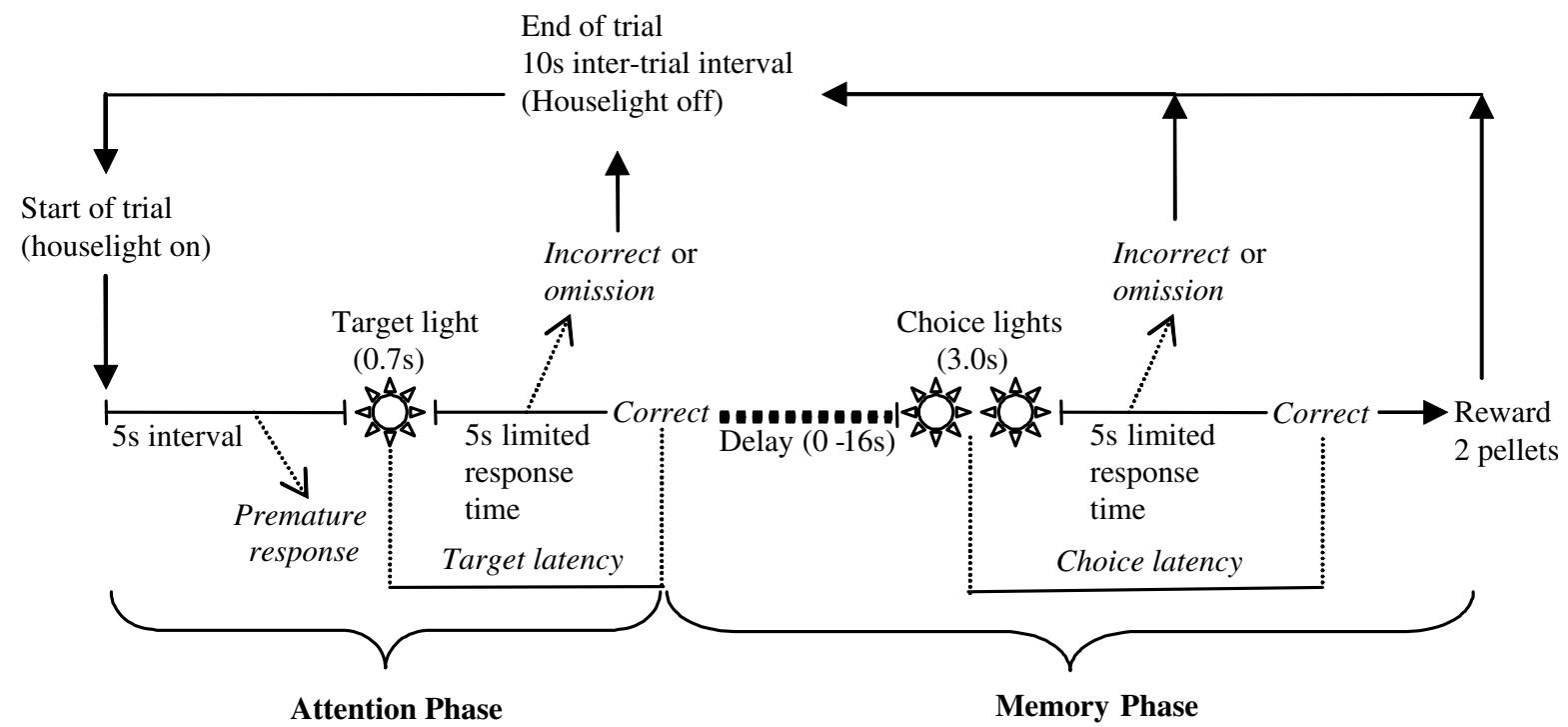

Figure I Schematic illustration of events in a single trial on the baseline version of the CAM task. Performance measures are indicated by italics.

phase was pseudorandomized across delays. The rat was rewarded with two pellets if it made a nose poke response in the choice hole that was the same as the original target light (correct choice response) while it was illuminated and after for $5 \mathrm{~s}$ (the limited hold period). A nose poke response in the 'distractor' choice hole or in any of the nonilluminated holes (incorrect choice response) or a failure to respond (choice omission) resulted in the termination of the trial and no food was delivered. The next trial began after an intertrial interval of darkness for $10 \mathrm{~s}$ after which the houselight was illuminated. Each session consisted of 100 trials.

Given the demanding requirements of the CAM task, it took approximately 4-6 months to train animals to asymptotic levels of performance. Therefore, initial training was conducted according to two phases. The animals were first trained to detect the target; thus the stimulus duration and limited hold period were both set at $1 \mathrm{~min}$. These variables were altered on subsequent sessions according to the animal's performance until the animal was able to detect a target duration of $0.7 \mathrm{~s}$. The animal was required to attain $>80 \%$ correct responses accompanied by $<20 \%$ omissions over five consecutive sessions within a $30 \mathrm{~min}$ session time. Approximately 25 sessions were required for the animals to attain this criterion.

Following successful training of the target phase, the delay intervals were instituted between the target (attention) and the choice (memory) phases of the task. During initial training, the delay was programmed at ' 0 ' $s$ for the entire session although the 'real' delay depended on the rats' latency to respond. The animal was rewarded for making a correct 'target' response and a correct 'choice' response. When animals were able to complete $>70 \%$ correct choice responses at the ' 0 ' $s$ delay for five consecutive days, the reward pellet following the correct target was removed; thus animals were only rewarded for making a correct choice response in the memory phase only. Additional delays of $0-16 \mathrm{~s}$ were then introduced according to the animal's performance. When rats were showing reliable performance across five consecutive days with a criterion of $\geqslant 70 \%$ correct during the target phase and at least $60 \%$ correct during the choice phase, the animals were ready for surgery. Approximately 90 sessions were required to attain this criterion.

Following implantation of guide cannulae in the mPFC, animals were retested on the baseline schedule until stable performance was obtained ( 7 days) after which they were habituated to the infusion procedure with two mock infusions for 2 days. Animals were then tested on the CAM task using a signal duration of $0.7 \mathrm{~s}$, following infusion with a selective $\mathrm{D}_{1}$ receptor agonist (SKF 81297) at all doses $(0.01,0.06$, or $0.3 \mathrm{mg} /$ $\mathrm{kg}$ ). In order to make comparisons with studies where short durations were used (eg Granon et al, 2000), the procedure was repeated in the same animals using a signal duration of $0.5 \mathrm{~s}$. See drug preparation and experimental design for counterbalanced sequence of drug infusions.

\section{Performance Measures}

Several performance measures were recorded for each phase for each trial. For the target (attention) phase, the following measures were calculated:

(i) Attentional accuracy was the number of correct target responses/total number of target responses expressed as a percentage (chance performance $=20 \%$ ). Thus, this measures errors of commission without including errors of omission.

(ii) Errors of target omission were also recorded for this phase as the number of trials on which no response was made expressed as a percentage. This measure reflects possible failures in detection.

(iii) Premature responses were the number of nose poke responses in the apertures during the interval prior to the onset of the target. This measure reflects possible deficits in impulse control and is related to response preparation. 
(iv) Target response latency was defined as the time between the onset of the visual target and the point at which the animal made a correct target response.

For the choice (memory) phase, the following measures were calculated:

(i) Choice accuracy was the number of correct choice responses/total number of choice responses expressed as a percentage for each delay (chance performance $=50 \%$ )

(ii) Choice response latency was the time from when the animal made the last nose poke in the food magazine after the delay to when the animal made a correct choice response.

(iii) Magazine latency was the time between the correct choice response and the time the rat entered the food magazine to collect its food reward.

\section{Surgery}

Cannulae implantation. After training on the CAM task, animals underwent stereotaxic implantation of chronic double guide cannula. Each guide cannula consisted of two 22-guage metal tubes (inner diameter: $0.39 \mathrm{~mm}$ ) that were $1.5 \mathrm{~mm}$ apart, projecting $3 \mathrm{~mm}$ from the plastic square pedestal (Plastics One, USA). Animals were deeply anaesthetized by an intramuscular injection of xylazine (Rompun, Vet Drug, Bury St Edmunds, UK; $10 \mathrm{mg} / \mathrm{kg}$ ) and ketamine (Ketaset, Vet Drug, Bury St Edmunds, UK; $50 \mathrm{mg} / \mathrm{kg}$ ) and placed in a stereotaxic frame fitted with atraumatic bars (David Kopf Instruments, Tujanga, CA, USA). The incisor bar was set at $-3.3 \mathrm{~mm}$. A small quantity of ophthalmic ointment (Lacri-Lube; Allergan, UK) was gently wiped over each eye to prevent desiccation of the corneal surfaces. The scalp was retracted to expose the skull and craniotomies were made directly above the target region of the brain. The guide cannulae was mounted on the arm of the stereotaxic frame and was lowered through the craniotomies at the following coordinates from bregma: AP $+3.0, L+/-0.7, \mathrm{DV}-2.2$ (from dura). The cannula was then implanted and affixed with dental cement and stainless sterile screws that served to hold the cannula in place. Sterile (dummy) stylets (Plastic One, USA) were introduced in the guide cannula to prevent occlusion. Particular care was taken to minimize infection. Therefore, during a 10-day recovery period, the dummy stylets were changed every other day. Rats were housed individually for the subsequent testing period. A total of 14 rats were cannulated.

Microinfusion procedure. Following postoperative recovery, rats were initially adapted to two mock infusion protocols to minimize any stress associated with the procedure. Rats were gently restrained while the dummy stylets were removed and replaced with a 28-gauge (inner diameter: $0.18 \mathrm{~mm}$, outer diameter: $0.36 \mathrm{~mm}$ ) stainless steel double injector extending $1.5 \mathrm{~mm}$ beyond the tip of the guide cannula (Plastics One, USA). The double injectors were connected by Portex fine bore polythene tubing (Portex Ltd, Kent, UK) to two $10 \mu \mathrm{l}$ precision syringes (SGE, UK) mounted in a Harvard Apparatus infusion pump.
Drug or vehicle was infused bilaterally in a volume of $0.5 \mu \mathrm{l}$ over $2 \mathrm{~min}$. The cannulae were left in place for a further $2 \mathrm{~min}$ before behavioral testing.

\section{Drug Preparation and Experimental Design}

SKF 81297 (RBI, Sigma, UK) was dissolved in aCSF (artifical cerebrospinal fluid). The composition of the aCSF was as follows (in $\mathrm{mM}$ ): $\mathrm{NaCl}(147), \mathrm{KCl}(3), \mathrm{MgCl}_{2}$ (1), $\mathrm{CaCl}_{2}$ (1.3), $\mathrm{NaH}_{2} \mathrm{PO}_{4} \cdot 2 \mathrm{H}_{2} \mathrm{O}(0.2), \mathrm{NaHPO}_{4}(1.3)$, and $75 \mathrm{ml}$ of double distilled water; $\mathrm{pH}$ 7.4. The doses of SKF 81297 were chosen according to the animals' behavior. In the first instance, rats received counterbalanced infusions of vehicle or a dose of $0.01 \mu \mathrm{g}$ SKF 81297. Then, they were further challenged with a higher dose of $0.06 \mu \mathrm{g}$ also counterbalanced with vehicle. In order to limit the number of infusions, the final dose of $0.3 \mu \mathrm{g}$ was compared with the vehicle data from the previous infusion. Importantly, this comparison, with the most recent assessment of vehicle, allowed us to guard against slight drift in the baseline. Drug test days were followed by a drug free day of no testing. Animals were then tested on the baseline schedule until performance stabilized before the next treatment.

\section{Data Analysis}

Data for each variable were subjected to repeated measures of analysis of variance (ANOVA) using the SPSS statistical package, version 9.0. (SPSS Inc, Chicago, IL, US). Data were initially explored using 'boxplots' and tests of homogeneity of variance so that outliers were identified and skewed data, which violate the distribution requirement of the ANOVA were transformed appropriately (arcsine, square root or logarithmic) as recommended by Winer (1971). Homogeneity of variance across groups was assessed by the Mauchly Sphericity Test. When data sets significantly violated this requirement for a repeated measures design, the Huynh-Feldt epsilon was used to calculate a more conservative $p$-value for each F-ratio. The criterion for statistical significance was a probability level of $p<0.05$. The within subject factors included dose (two levels: vehicle and $0.01,0.06$, or $0.3 \mu \mathrm{g}$ ) and delay (four levels: $0,4,8$, and $16 \mathrm{~s})$.

\section{Histology}

At the conclusion of the behavioral testing, the animals were perfused transcardially with $0.9 \%$ saline followed by $10 \%$ formal saline. After dehydration by immersion in $20 \%$ sucrose, the brains were sectioned on a freezing microtome at $60 \mu \mathrm{m}$ thickness. Every second section was mounted on glass slides and stained with Cresyl Violet. The sections were used to verify cannulae placement and to assess the extent of lesion-induced neuronal loss.

\section{RESULTS}

\section{Histological Analysis}

Figure $2 \mathrm{a}$ provides a schematic diagram of the position of the cannula tips within the mPFC. The cannulae tips were located within the region of the $\mathrm{mPFC}$ that included the 
dorsal anterior cingulate $(\mathrm{Cg} 1)$ and prelimbic $(\mathrm{PrL})$ areas ( +3.2 from bregma). Following cannulation, one animal died during recovery, a second rat died due to a respiratory infection, and a third rat was removed from testing due to the frequent occurrence of epileptic seizures unrelated to drug infusions. A total of 11 rats were used for this study.

\section{Behavioral Results}

Effect of intra-mPFC SKF 81297 at 0.7 s signal duration.

$0.01 \mu \mathrm{g}$ dose: Figure $3 \mathrm{a}$ shows there was no effect of drug on attentional accuracy $(F(1,10)=0.24, p>0.05)]$. Nor did this dose of drug have any effect on the number of target omissions $(F(1,10)=0.46, p>0.05$; means $( \pm S E M)$ : veh, $9 \%(0.41)$, drug, $7 \%(0.45))$. While there was an overall effect of delay $(\mathrm{F}(3,30)=4.45, p<0.01)$, there was no effect of dose on choice response accuracy during the memory phase $(F(1,10)=0.11, p>0.05$; see Figure $3 b)$. There was no effect of this dose on premature responding prior to the onset of the target stimulus ( $p>0.05$; means $( \pm$ SEM): veh, 69 (4.0), drug, 78 (4.6)). These animals were not impaired in terms of latency to respond to the target, or for choice, or to collect food reward $(\mathrm{F}<1)$.

$0.06 \mu \mathrm{g}$ dose: Figure $3 \mathrm{c}$ shows that the $0.06 \mu \mathrm{g}$ dose of SKF 81297 produced a significant enhancement of attentional accuracy $(\mathrm{F}(1,10)=6.37, p<0.05)$. There was no effect of this dose on target omissions $(p>0.05$; means $( \pm$ SEM): veh, $10(0.5)$, drug, $11(0.7))$. However, in addition to the overall effect of delay during the memory phase $(\mathrm{F}(3,30)=3.46, p<0.05)$, there was also a significant effect of dose on choice accuracy $(\mathrm{F}(1,10)=5.51, p<0.05)$. The pattern of data in Figure $3 \mathrm{~d}$ suggest that this enhanced choice accuracy was primarily at the 4 and $8 \mathrm{~s}$ delays, although there was no significant dose $\times$ delay interaction on the measure $(\mathrm{F}(3,30)=1.08, p>0.05)$. Unlike the lower dose, the $0.06 \mu \mathrm{g}$ dose of SKF 81297 significantly reduced the number of premature responses $(\mathrm{F}(1,10)=9.55$, $p<0.01$; means ( \pm SEM): veh, 88 (4.3), drug, 49 (3.4)).

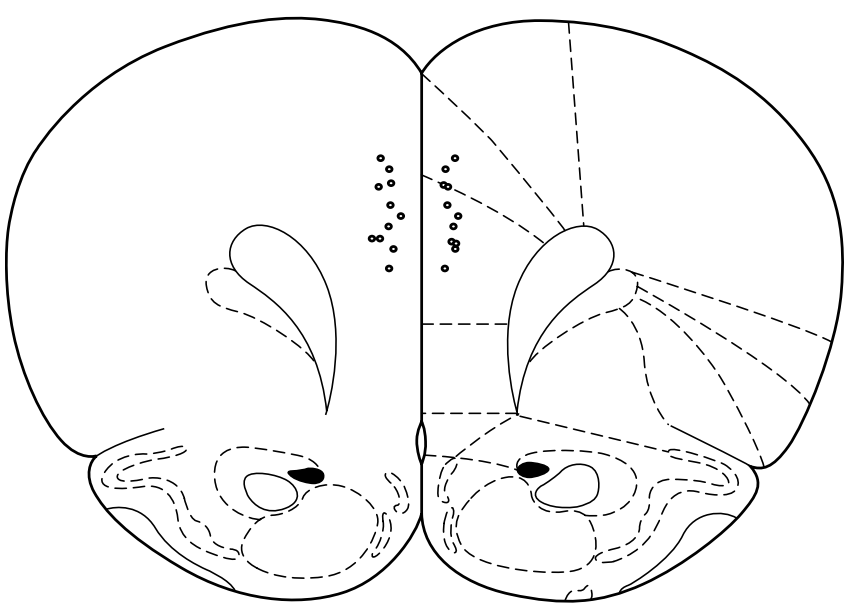

Figure 2 Schematic diagram showing location of cannulae injector tips (circles) that were located within the dorsal $(\mathrm{Cg} \mathrm{I})$ and medial $(\mathrm{PrL})$ region of the mPFC for rats used in this study. Atlas plates adapted from Paxinos and Watson (1997). Section $+3.2 \mathrm{~mm}$ from bregma.
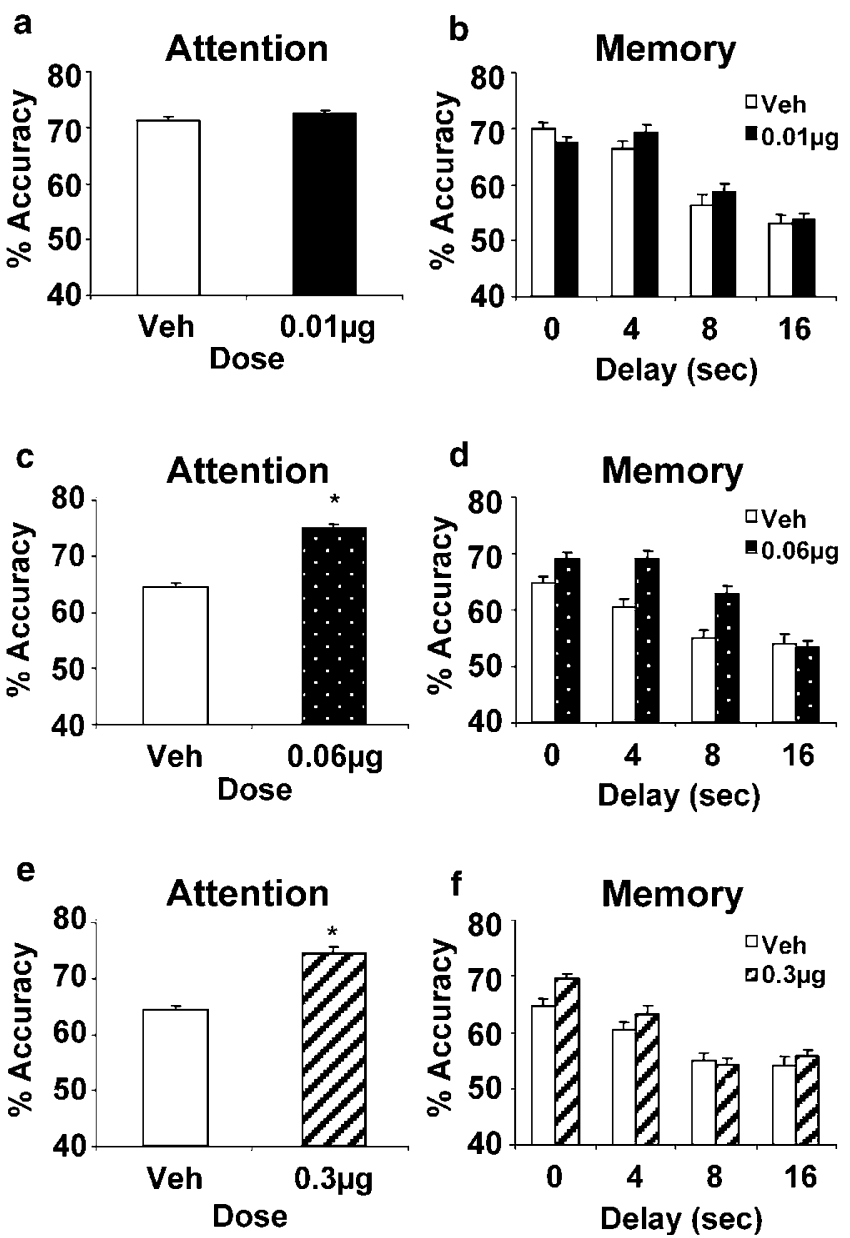

Figure 3 Mean performance ( \pm SEM) of intra-mPFC SKF 81297 infusions on attention and memory phases of the CAM task when the target stimulus duration was $0.7 \mathrm{~s}$. The same data are shown for vehicle in graphs (c-f). (*sig $p<0.05)$.

Speed of responding to the target or choice stimuli was not affected $(p>0.05)$. Magazine latency during the drug infusion was slower relative to vehicle but this was found not to be significant $(\mathrm{F}(1,10)=3.67, p=0.08$; means in csec ( \pm SEM: veh, 86.07 (2.1), drug, $95.60(2.2)$ ).

$0.3 \mu \mathrm{g}$ dose: The behavioral effects of this high dose were analyzed against the specific vehicle data counterbalanced for the $0.06 \mu \mathrm{g}$ dose because it was the most recent vehicle data obtained (see Drug preparation and experimental design). Similar to the $0.06 \mu \mathrm{g}$ dose, the $0.3 \mu \mathrm{g}$ dose increased attentional accuracy $(\mathrm{F}(1,10)=14.17, p<0.01$; see Figure 3e] with no associated effect on omissions $[\mathrm{F}(1,10)=0.14, p>0.05)$. However, despite the enhancement in attention, the $0.3 \mu \mathrm{g}$ dose did not affect performance of these animals during the memory phase $(F(1,10)=0.54, p>0.05$; see Figure $3 f)$. All animals showed a delay-dependent effect with percent correct accuracy declining with increasing delay $(\mathrm{F}(3,30)=5.84, p<0.001)$. Premature responding significantly declined at the $0.3 \mu \mathrm{g}$ dose $(\mathrm{F}(1,10)=6.95, p<0.05$; means $( \pm$ SEM $)$ : veh, $88(4.3)$, drug, 60 (3.3)). No other differences were observed during this manipulation $(\mathrm{F}<1)$. 
Effect of intra-mPFC SKF 81297 at 0.5 s signal duration. Animals were retested with the $0.01,0.06$, and $0.3 \mu \mathrm{g}$ doses at a short target duration of $0.5 \mathrm{~s}$ in order to examine behavioral effects when animals were challenged with an increased attentional load. Furthermore, this manipulation allowed comparisons to be made with a previous study in which $\mathrm{D}_{1}$ receptor agonists were infused into the mPFC when the stimulus duration was set at $0.5 \mathrm{~s}$ (see Granon et al, 2000).

$0.01 \mu \mathrm{g}$ dose: At this low dose, there was no differential effect of drug on attentional accuracy $(\mathrm{F}(1,10)=2.36$, $p>0.05$; see Figure $4 a)$ or omissions $(F(1,10)=1.50$, $p>0.05$ ). Figure $4 \mathrm{~b}$ shows a delay-dependent reduction in accuracy when animals were under vehicle but there was no overall effect of delay during the memory phase $(\mathrm{F}(3,30)=1.97, p>0.05)$. However, the pattern of data suggests that the low dose of SKF 81297 improved performance at the longest delays although no significant dose $\times$ delay interaction was obtained for this measure $(\mathrm{F}(3,30)=0.51, p>0.05)$. No other effects were observed at this dose.

$0.06 \mu g$ dose: Figure $4 \mathrm{c}$ shows that this dose significantly improved attentional accuracy relative to vehicle $(\mathrm{F}(1,10)=5.59, p<0.05)$. The number of omissions was not affected by this dose $(F(1,10)=0.42, p>0.05)$. All animals showed a delay-dependent reduction in accuracy across delays $(\mathrm{F}(3,30)=6.63, p<0.01)$. Figure $4 \mathrm{~d}$ shows a tendency for these animals to increase accuracy at the long delays under the $0.06 \mu \mathrm{g}$ dose although this effect was found to be nonsignificant $(F(1,10)=1.22, p>0.05)$. Premature responding was not affected by this dose $(p<0.05)$. Also, these animals were not impaired in terms of latency to respond to the target, or for choice, or to collect food reward $(p<0.05)$.

$0.3 \mu \mathrm{g}$ dose: The $0.3 \mu \mathrm{g}$ dose like the $0.06 \mu \mathrm{g}$. dose significantly improved performance of attentional accuracy $(\mathrm{F}(1,10)=13.18, p<0.05$; see Figure $4 \mathrm{e})$. The number of target omissions was not affected $(\mathrm{F}(1,10)=0.09, p>0.05)$. However, during the memory phase, this dose impaired choice accuracy at the short delay and improved choice performance at the longest delays (see Figure $4 \mathrm{f}$ ) as revealed by a significant dose $\times$ delay interaction $(F(3,30)=3.64$, $p<0.05)$. At this high dose, premature responding was not affected $(\mathrm{F}(1,10)=3.44, p>0.05)$ and nor was speed of responding to the target and choice stimuli $(p>0.05)$. Although latency to collect food reward was markedly reduced under the drug relative to vehicle (means in csec ( \pm SEM): veh, 190.41 (32.9), drug, $92.45(5.5)$ ), this was found not to be significant $(\mathrm{F}(1,10)=1.36, p>0.05)$.

To summarize, at the $0.7 \mathrm{~s}$ target stimulus duration, infusions of SKF 81297 enhanced attentional accuracy at the middle $(0.06 \mu \mathrm{g})$ and high $(0.3 \mu \mathrm{g})$ doses although the vehicle data for the latter dose was subject to variability. However, only the $0.06 \mu \mathrm{g}$ dose produced a facilitatory effect on choice accuracy in the memory phase. This enhanced response accuracy occurred in the absence of increased behavioral activity as both doses reduced premature responses prior to the onset of target and the speed of
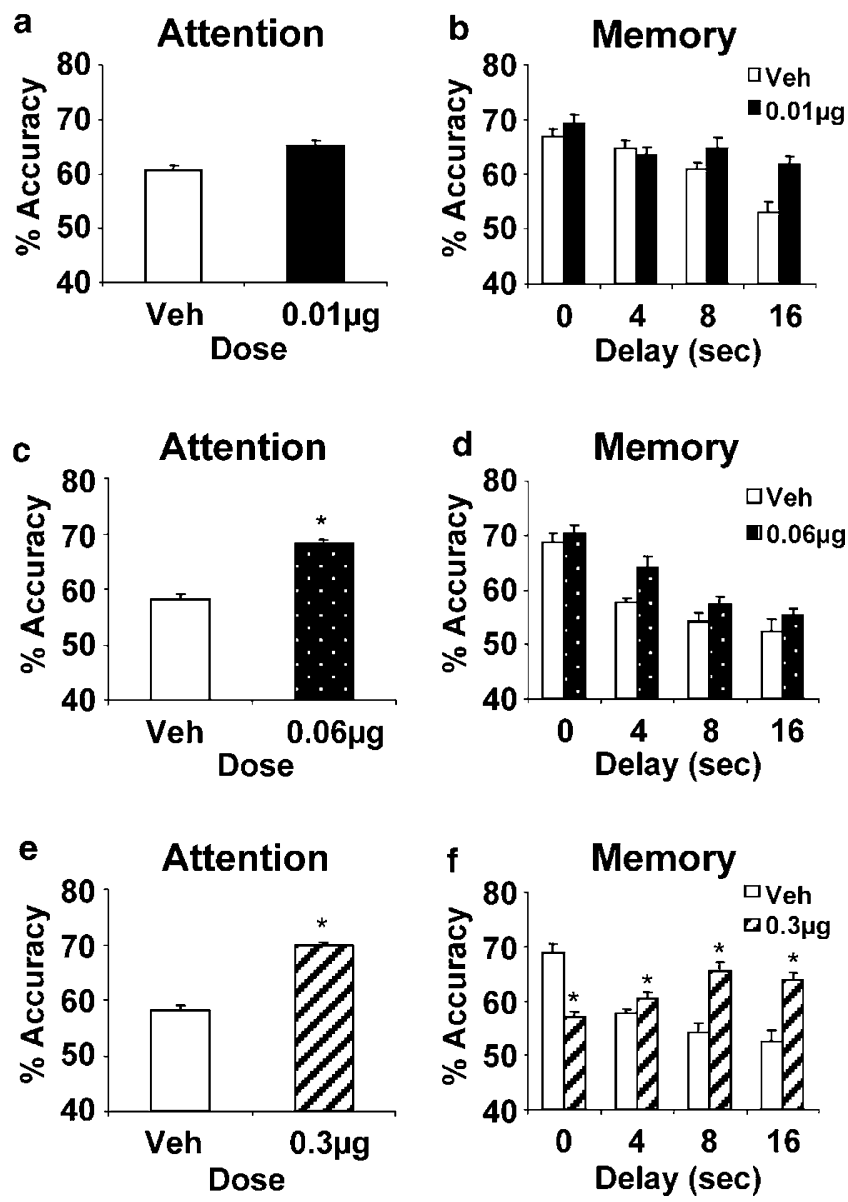

Figure 4 Mean performance ( \pm SEM) of intra-mPFC SKF 81297 infusions on attention and memory phases of the CAM task when the target stimulus duration was reduced to $0.5 \mathrm{~s}$. The same data are shown for vehicle in graphs $(c-f)$. (*sig $p<0.05)$

responding was also not impaired. Similarly, at the lower target duration of $0.5 \mathrm{~s}$, when the attentional demand was increased, the $0.06 \mu \mathrm{g}$ and $0.3 \mu \mathrm{g}$ doses of SKF 81297 improved attention to the target but only the high dose affected memory for the target in a way that impaired choice accuracy when performance was high ( $0 \mathrm{~s}$ delay) and improved choice accuracy when performance was low (16s delay).

\section{DISCUSSION}

The effect of intra-PFC DA receptor stimulation on attentional and memory performance in a novel combined attention-memory task (CAM) depended on the dose of the DA agonist (SKF 81297) and the attentional demands of the task. Reducing the duration of the visual target stimulus from 0.7 to $0.5 \mathrm{~s}$, impaired attentional performance, but without affecting omissions or response latency, thus ruling out motivational factors. The $\mathrm{D}_{1}$ agonist improved accuracy in the attentional phase at certain doses $(0.06$ and $0.3 \mu \mathrm{g})$ in each condition. This enhancement was not due to an improved capacity to hold the visual targets on-line because the rats mainly responded within the duration of the visual target (ie while it was still on) - thus a beneficial effect on 
attentional selection is indicated at this dose. By contrast, the low dose $(0.01 \mu \mathrm{g})$ did not affect attention where presumably performance was nearing asymptote and was less amenable to further improvement, particularly at the $0.7 \mathrm{~s}$ duration condition.

During the memory phase of the task, only when the target was relatively easy to detect $(0.7 \mathrm{~s})$ did the $0.06 \mu \mathrm{g}$ dose show any improvement in memory, showing the narrow range over which DA receptor stimulation may operate to enhance performance under certain conditions. Clearly, when attentional demands were low, supranormal stimulation of $D_{1}$ receptors by increasing the dose $(0.3 \mu \mathrm{g})$ produced no beneficial effect on memory performance. However, in the difficult condition $(0.5 \mathrm{~s})$, the high $0.3 \mu \mathrm{g}$ dose impaired memory performance when it was already good (at the ' $0 \mathrm{~s}$ ' delay) and improved memory when it was bad at the long delays. Altered plasticity following repeated injections is unlikely to explain the differential memory effects, given the equivalent attentional improvement following $\mathrm{D}_{1}$ treatment. We believe this to be the first study to demonstrate improved attentional accuracy and a delaydependent modulation of working memory performance associated with $D_{1}$ receptors.

Effective performance on the CAM task requires several component cognitive processes. The animals have to monitor the visual array, selectively detect the target stimulus and then hold on-line its location for a variable delay before using that information to guide response selection. This complexity may explain why baseline accuracy scores during the attentional phase remained moderately low $(60-70 \%)$ even when the stimulus duration was $0.7 \mathrm{~s}$ compared to the more difficult $0.5 \mathrm{~s}$. Importantly, however, this allows direct comparison with Granon et al (2000), in which intra-PFC infusions of a partial $D_{1}$ agonist (SKF 38393) only improved attentional accuracy in animals in the 5CSRTT when baseline levels were relatively low (about 70\%). Our observation that the full DA receptor agonist SKF 81297 improved performance in animals with a similar baseline clearly extends these previous findings. This effect was specific to $D_{1}$ receptors, as intra-PFC infusions of sulpiride, a $\mathrm{D}_{2}$ receptor antagonist, produced no effects. As the diffusion of a labeled $D_{1}$ receptor antagonist infused into the same PFC site was restricted to the dorsal and medial PFC cortex (see Granon et al, 2000), we assume that the present effects were probably limited to this region.

$\mathrm{D}_{1}$ receptor agonists may optimize performance of demanding tasks, by 'tuning' prefrontal cortical pyramidal cell activity (Williams and Goldman-Rakic, 1995; Yang and Seamans, 1996; Seamans et al, 1997). However, although enhanced attention can improve short-term memory performance, the functional relationship between these component cognitive processes may be determined by the degree of prefrontal DA activity that modulates optimal performance (Roberts et al, 1994; Collins et al, 1998; Phillips et al, 2004). That different cognitive processes govern accurate performance in the CAM task and indeed, other delayed response tasks, suggest that working memory deficits cannot be attributed to a single factor, such as holding information on-line.

There were no improvements in response latencies or on motivational measures such as magazine latency, suggesting that the PFC DA may specifically enhance discriminative performance rather its speed or vigour. However, the $D_{1}$ agonist significantly reduced the number of 'impulsive' premature nose pokes prior to the onset of the target stimulus. In contrast, DA depletion in subcortical regions such as the nucleus accumbens reduces premature responding (Cole and Robbins, 1989), whereas intra-accumbens infusions of D-amphetamine (a nonspecific, indirect DA agonist) increase impulsive responding, without affecting discrimination per se (Robbins and Sahakian, 1983; Cole and Robbins, 1989). This 'impulsive' behavior is thus probably modulated by subcortical systems including the ventral striatum, whose functions may be regulated via their cortical connections (Alexander et al, 1990; Taylor and Jentsch, 2001). There is considerable evidence for corticalsubcortical reciprocity of function within the dopamine projections (Carter and Pycock, 1980; Pycock et al, 1979, 1980; Glowinski et al, 1988; Roberts et al, 1994) consistent with the opposed functional effects of DA agonists observed in this and earlier studies (Cole and Robbins, 1989) and therefore, we cannot be certain that the PFC DA stimulation may have affected other brain regions (eg striatum). Nonetheless, that only lesions of the ventral infralimbic region of the medial prefrontal cortex increase premature responding in the 5CSRTT, and only lesions of the dorsal pre-genual anterior cingulate cortex produce deficits in response accuracy (Passetti et al, 2002; Chudasama et al, 2003) suggests that DA projections to selective frontal areas may have specific modulatory roles in attention and behavioral control that are somehow integrated to produce optimal executive performance. Evidently, in addition to improving selective attention to a target, increasing PFC DA activity also serves advantageously to reduce impulsive responding, and this finding may be relevant to disorders of executive attention such as attention deficit/hyperactivity disorder (ADHD) where frontal as well as striatal abnormalties are apparent (Ernst et al, 1998; Rubia et al, 1999; Mehta et al, 2001; Solanto et al, 2001).

The finding that PFC infusions of a high dose of SKF81297 enhanced poor memory for the visual target at the extended delays but impaired good memory at the short delays clearly demonstrates the modulatory role of DA in working memory (Arnsten et al, 1994; Cai and Arnsten, 1997). $D_{1}$ agonists including SKF 81297 are typically characterized by an inverted ' $U$ '-shaped DA function where efficiency of cognitive performance is related to the level of $\mathrm{D}_{1}$ receptor stimulation (Robbins, 1985; Williams and Goldman-Rakic, 1995; Arnsten, 1998; Zahrt et al, 1997). However, the evidence for this notion is derived from studies that have shown working memory impairments following intracortical $\mathrm{D}_{1}$ agonist infusions and the blocking of this effect by intracortical or systemic administration of $\mathrm{D}_{1}$ receptor antagonists (eg Arnsten et al, 1994; Zahrt et al, 1997). Although our data are consistent with Floresco and Phillips (2001) who showed delay-dependent effects of PFC DA receptor stimulation in a delayed spatial win-shift task (ie poor memory retrieval was made better and good memory retrieval was made worse), these authors used separate groups of animals for each delay condition in a between-subject design. In this study, we have shown that a $\mathrm{D}_{1}$ agonist produced both beneficial and detrimental effects in working memory that depended on the baseline 
performance at each delay within the same group of rats when presented with a mixture of short and long delays within the same test session. These baseline-dependent effects are more akin to the concept of 'rate-dependency' which assumes an inverse relationship between the control rate of responding and the drug effect (Dews, 1977; Dews and Wenger, 1977; Robbins and Sahakian, 1979). Thus, individuals with hypo- or hyperactive states may exhibit 'rate-dependent' effects such that high rates of responding may decrease overall, whereas low rates of responding may increase following psychostimulant administration. These 'rate-dependent' effects may arise from how memory processes are affected by elevated stress or arousal. For example, high arousal caused by $\mathrm{D}_{1}$ receptor stimulation may provide a more deeply encoded or salient trace leading to superior memory performance at the long delays. However, this might be at the cost of greater interference from such strengthened traces at shorter delays. This speculation is consistent with human studies showing that arousing conditions such as white noise or emotional material can impair short-term recall but benefit longerterm retention (Eysenck, 1982). Our data, together with those of Floresco and Phillips (2001), are thus perhaps consistent with the existence of independent phases of memory in rats (Kesner et al, 1981) that are evidently susceptible to modulation by mesocortical DA.

The present findings support the conclusion that DA projections to the prefrontal cortex differentially regulate attention (Granon et al, 2000; Dalley et al, 2002) and working memory performance (Sahakian et al, 1985; Zahrt et al, 1997; Williams and Goldman-Rakic, 1995; Seamans et al, 1998; Floresco and Phillips, 2001) and is in keeping therefore with the hypothesis that there exist optimal levels of DA release (or activation) in the PFC for efficient cognitive performance. Our data also suggest, however, that the modulatory nature of the PFC DA may have to be considered with respect to its interactions with different optima of arousal. Overall, the beneficial effects of DA in cortical function can provide promising therapeutic possibilities of drug treatment for many cognitive and psychiatric disorders including age-related cognitive decline, ADHD, and schizophrenia, each of which are associated with abnormal DA transmission in the PFC (Lewis and Akil, 1997; Okubo et al, 1997; Mehta et al, 2001).

\section{ACKNOWLEDGEMENTS}

This work was supported by a Programme grant from the Wellcome Trust (TWR) completed within the Medical Research Council Centre for Behavioral and Clinical Neuroscience. YC was supported by Cambridge Cognition. We thank Dr RN Cardinal for his help with programming. YC is now at Laboratory of Neuropsychology, NIH/NIMH, 49 Convent Drive, Building 49, Room 1B80, Bethesda, MD 20892-4415.

\section{REFERENCES}

Alexander GE, Crutcher MD, DeLong MR (1990). Basal gangliathalamocortical circuits: parallel substrates for motor, oculomotor, 'prefrontal' and 'limbic' functions. Prog Brain Res 85: 119-146.
Arnsten AF, Cai JX, Murphy BL, Goldman-Rakic PS (1994). Dopamine D1 receptor mechanisms in the cognitive performance of young adult and aged monkeys. Psychopharmacology 116: $143-151$.

Arnsten AFT (1997). Catecholamine regulation of the prefrontal cortex. J Psychopharmacol 11: 151-162.

Arnsten AFT (1998). Catecholamine modulation of prefrontal cortical cognitive function. TICS 2: 436-447.

Arnsten AFT, Goldman-Rakic PS (1990). Stress impairs prefrontal cortex cognitive function in monkeys: role of dopamine. Soc Neurosci Abstr 16: 164.

Awh E, Jonides J (2001). Overlapping mechanisms of attention and spatial working memory. TICS 5: 119-126.

Brozoski TJ, Brown RM, Rosvold HE, Goldman PS (1979). Cognitive deficit caused by regional depletion of dopamine in prefrontal cortex of rhesus monkey. Science 205: 929-932.

Cai JX, Arnsten AF (1997). Dose-dependent effects of the dopamine D1 receptor agonists A77636 or SKF81297 on spatial working memory in aged monkeys. J Pharmacol Exp Ther 283: 183-189.

Carli M, Robbins TW, Evenden JL, Everitt BJ (1983). Effects of lesions to ascending noradrenergic neurons on performance on a 5-choice serial reaction time task in rats: implications for theories of dorsal noradrenergic bundle function based on selective attention and arousal. Behav Brain Res 9: 361-380.

Carter CJ, Pycock CJ (1980). Behavioural and biochemical effects of dopamine and noradrenaline depletion within the medial prefrontal cortex of the rat. Brain Res 192: 163-176.

Chudasama Y, Passetti F, Rhodes SEV, Lopian D, Desai A, Robbins TW (2003). Dissociable aspects of performance on the 5 choice serial reaction time task following lesions of the dorsal anterior cingulate, infralimbic and orbitofrontal cortex in the rat: differential effects on selectivity, impulsivity and compulsivity. Behav Brain Res 146: 105-119.

Cole BJ, Robbins TW (1989). Effects of 6-hydroxydopamine lesions of the nucleus accumbens septi on performance of a 5-choice serial reaction time task in rats: implications for theories of selective attention and arousal. Behav Brain Res 33: 165-179.

Collins P, Roberts AC, Dias R, Everitt BJ, Robbins TW (1998). Perseveration and strategy in a novel spatial self-ordered sequencing task for non-human primates: effects of excitotoxic lesions and dopamine depletions of the prefrontal cortex. J Cog Neurosci 10: 332-354.

Cools R, Stefanova E, Barker RA, Robbins TW, Owen AM (2002). Dopaminergic modulation of high-level cognition in Parkinson's disease: the role of prefrontal cortex revealed by PET. Brain 125: 584-594.

Dalley JW, Theobald DE, Pereira EAC, Li PMMC, Robbins TW (2002). Specific abnormalities in serotonin release in the prefrontal cortex of isolation reared rats measured during behavioural performance of a task assessing visuospatial attention and impulsivity. Psychopharmacology 164: 329-340.

Dews PB (1977). Rate-dependency hypothesis. Science 198: $1182-1183$.

Dews PB, Wenger GR (1977). Rate-dependency of the behavioral effect of amphetamine. In: Thompson T, Dews PB (eds). Advances in Behavioral Pharmacology, Vol 1. Academic Press: New York. pp 167-227.

Ernst M, Zametkin AJ, Matochik JA, Jons PH, Cohen RM (1998). DOPA decarboxylase activity in attention deficit hyperactivity disorder adults. A [fluorine-18]fluorodopa positron emission tomographic study. J Neurosci 18: 5901-5907.

Eysenck MW (1982). Attention and Arousal, Cognition and Performance. Springer-Verlag: New York. pp 47-66.

Floresco SB, Phillips AG (2001). Delay-dependent modulation of memory retrieval by infusion of a dopamine D1 agonist into the rat medial prefrontal cortex. Behav Neurosci 113: 934-939. 
Glowinski H, Cheramy A, Romo R, Barbeito L (1988). Presynaptic regulation of dopaminergic transmission in the striatum. Cell Mol Neurobiol 8: 7-17.

Goldman-Rakic PS (1987). Circuitry of primate prefrontal cortex and regulation of behaviour by representational memory. In: Plum F, Mountcastle V (eds). Handbook of Physiology: The Nervous System. The American Psychological Society: Bethesda, MD. pp 373-417.

Granon S, Passetti F, Thomas KL, Dalley JW, Everitt BJ, Robbins TW (2000). Enhanced and impaired attentional performance after infusion of $\mathrm{D} 1$ dopaminergic receptor agents into rat prefrontal cortex. J Neurosci 20: 1208-1215.

Kesner RP, Bierley RA, Pebbles P (1981). Short-term memory: the role of D-amphetamine. Pharmacol Biochem Behav 15: 673-676.

Lewis DA, Akil M (1997). Cortical dopamine in schizophrenia: strategies for postmortem studies. J Psychiatr Res 31: 175-195.

Mehta MA, Sahakian BJ, Robbins TW (2001). Comparative psychopharmacology of methylphenidate and related drugs in human volunteers, patients with ADHD and experimental animals. In: Solanto MV, Arnsten AFT, Castellanos FX (eds). Stimulant Drugs and ADHD: Basic and Clinical Neuroscience. Oxford UP: New York. pp 303-331.

Muir JL, Everitt BJ, Robbins TW (1996). The cerebral cortex of the rat and visual attentional function: dissociable effects of mediofrontal, cingulate, anterior dorsolateral, and parietal cortex lesions on a five-choice serial reaction time task. Cerebral Cortex 6: 470-481.

Okubo Y, Suhara T, Suzuki K, Kobayashi K, Inoue O, Terasaki O et al (1997). Decreased prefrontal dopamine D1 receptors in schizophrenia revealed by PET. Nature 385: 634-636.

Parasuraman R (2000). The attentive brain: issues and prospects. In: Parasuraman $\mathrm{R}$ (ed). The Attentive Brain. MIT Press: Cambridge, MA. pp 3-15.

Paxinos G, Watson C (1997). The Rat Brain in Stereotaxic Coordinates. Academic Press: New York.

Passetti F, Chudasama Y, Robbins TW (2002). The frontal cortex of the rat and visual attentional performance: dissociable functions of distinct medial prefrontal subregions. Cerebral Cortex 12: 1254-1268.

Phillips AG, Ahn S, Floresco SB (2004). Magnitude of dopamine release in the medial prefrontal cortex predicts accuracy of memory on a delayed response task. J Neurosci 24: 547-553.

Pycock CJ, Carter CJ, Kerwin RW (1979). Possible involvement of frontal-cortical catecholamine systems in the regulation of neurotransmitter mechanisms at sub-cortical sites in the rat brain. Biochem Soc Trans 7: 140-143.

Pycock CJ, Kerwin RW, Carter CJ (1980). Effect of lesion of cortical dopamine terminals on subcortical dopamine receptors in rats. Nature 286: 74-76.

Robbins TW (1985). Neuropsychological evaluation of higher cognitive function in animals and man: can psychopharmacology contribute to neuropsychology?. In: Iversen SD (ed). Psychopharmacology: Recent Advances and Future Prospects. Oxford OU: Oxford. pp 155-169.

Robbins TW (2000). Chemical neuromodulation of frontalexecutive functions in humans and other animals. Exp Brain Res 133: 130-138.
Robbins TW, Sahakian BJ (1979). 'Paradoxical' effects of psychomotor stimulant drugs in hyperactive children from the standpoint of behavioural pharmacology. Neuropharmacology 18: 931-950.

Robbins TW, Sahakian BJ (1983). Behavioural effects of psychomotor stimulant drugs: clinical and neuropsychological implications. In: Creese I (ed). Stimulants, Neurochemical, Behavioral and Clinical Perspectives. Raven Press: New York. pp 301-338.

Roberts AC, De Salvia MA, Wilkinson LS, Collins P, Muir JL, Everitt BJ et al (1994). 6-Hydroxydopamine lesions of the prefrontal cortex in monkeys enhance performance on an analog of the Wisconsin Card Sort Test: possible interactions with subcortical dopamine. J Neurosci 14: 2531-2544.

Rubia K, Overmeyer S, Taylor E, Brammer M, Williams SC, Simmons A et al (1999). Hypofrontality in attention deficit hyperactivity disorder during higher-order motor control: a study with functional MRI. Am J Psychiatry 156: 891-896.

Sahakian BJ, Sarna GS, Kantamaneni BD, Jackson A, Hutson PH, Curzon G (1985). Association between learning and cortical catecholamines in non-drug-treated rats. Psychopharm 86: 339-343.

Sawaguchi T, Goldman-Rakic PS (1991). $\mathrm{D}_{1}$ dopamine receptors in prefrontal cortex: involvement in working memory. Science 251 : 947-950.

Seamans JK, Floresco SB, Phillips AG (1998). $D_{1}$ receptor modulation of hippocampal-prefrontal cortical circuits integrating spatial memory with executive functions in the rat. J Neurosci 18: 1613-1621.

Seamans JK, Gorelova NA, Yang CR (1997). Contributions of voltage-gated $\mathrm{Ca}^{2+}$ channels in the proximal versus distal dendrites to synaptic integration in prefrontal cortical neurons. J Neurosci 17: 5936-5948.

Simon H (1981). Dopaminergic A10 neurons and the frontal system. J Physiol (Paris) 77: 81-95.

Solanto MV, Arnsten AFT, Castellanos FX (2001). The neuroscience of stimulant drug action in ADHD. In: Solanto MV, Arnsten AFT, Castellanos FX (eds). Stimulant Drugs and ADHD: Basic and Clinical Neuroscience. Oxford UP: New York. pp 355-379.

Taylor JR, Jentsch D (2001). Stimulant effects on striatal and cortical dopamine systems involved in reward-related behaviour and impulsivity. In: Solanto MV, Arnsten AFT, Castellanos FX (eds). Stimulant Drugs and ADHD: Basic and Clinical Neuroscience. Oxford UP: New York. pp 104-133.

Williams GV, Goldman-Rakic PS (1995). Modulation of memory fields by dopamine $\mathrm{D}_{1}$ receptors in prefrontal cortex. Nature 376: 572-575.

Winer BJ (1971). Statistical Principles in Experimental Design. McGraw-Hill: New York.

Yang CR, Seamans JK (1996). Dopamine $D_{1}$ receptor actions in layers V-VI rat prefrontal cortex neurons in vitro: modulation of dendritic-somatic signal integration. J Neurosci 16: 1922-1935.

Zahrt J, Taylor JR, Mathew RG, Arnsten AF (1997). Supranormal stimulation of $\mathrm{D}_{1}$ dopamine receptors in the rodent prefrontal cortex impairs spatial working memory performance. J Neurosci 17: 8528-8535. 